\title{
Diaristas: "Novas Domésticas” em Tempos de Trabalho Precário?
}

Cleaning Ladies: "New maids" in the Time of Precarious Work?

\author{
Thiago Prisco \\ Cátia Siqueira Carvalho \\ Michelle Moreira Gomes ***
}

\begin{abstract}
Resumo:
O presente artigo visa discorrer acerca das transformações ocorridas no mundo do trabalho, que alteraram as relações profissionais e a dinâmica de vida das diaristas. Aborda a temática a partir de três eixos analíticos centrais, quais sejam: informalidade, gênero e direitos trabalhistas. Tal discussão está embasada em estudos sobre o mundo do trabalho, o trabalho feminino na esfera doméstica e em pesquisa com trabalhadoras deste universo profissional. Com isso, apresentaremos a precarização e a ausência de direitos inerentes ao trabalho das diaristas, revelando as expressões da questão social a que estão submetidas. Deste modo, a ocupação diarista é aqui compreendida como uma mutação do emprego doméstico, com alterações advindas das transformações ocorridas no mundo do trabalho.
\end{abstract}

Palavras-chave: Trabalho doméstico. Informalidade. Gênero. Diaristas.

\begin{abstract}
:
This article aims to discuss the changes occurring in the workplace, which modified the professional relationships and way of life of laborers. Approaches the issue from three central analytical axes, namely: informality, gender and labor rights. This discussion is based on research on the world of work, female labor in the domestic sphere and research workers in the professional world. Thus, we will present the precariousness and lack of labor rights for the laborers, revealing the terms of the social question to which they are submitted. Thus, the occupation cleaning ladies (diarist) is understood as a mutation domestic employment, with changes resulting from changes in the world of work.
\end{abstract}

Key-words: Work. Informality. Gender. Cleaning ladies.

\section{Introdução}

\footnotetext{
* Assistente Social. Prefeitura Municipal de Belo Horizonte. thiago_prisco@hotmail.com

** Assistente Social. catiasikeira@yahoo.com.br

${ }^{* * *}$ Assistente Social. gomesmichelle@bol.com.br
} 
O presente artigo apresenta uma discussão sobre o trabalho das diaristas no município de Belo Horizonte. Os objetivos do estudo são: refletir sobre o trabalho informal e seus efeitos sobre a vida dessas mulheres; conhecer a opinião das entrevistadas sobre o trabalho informal e como refletem sobre isso; além de investigar quais as razões que contribuem para que as diaristas trabalhem informalmente.

O interesse pelo tema também se deu pela necessidade de discorrer sobre a conjuntura atual, que tem reflexos nítidos sobre a questão social e acabou por alterar a dinâmica de vida de diversos profissionais, pois os modelos de produção vêm sendo modificados, assim como, as formas de inserção dos trabalhadores nos espaços sócioocupacionais. Desse modo, a importância da pesquisa está na atualidade da temática, nos dados obtidos por meio dela e no que a mesma oferece de novo nesse campo.

Para a realização deste estudo, foi desenvolvida uma pesquisa bibliográfica, com base em livros, capítulos de livros e artigos científicos. A bibliografia foi selecionada de acordo com os seguintes temas: mundo do trabalho, precarização das relações trabalhistas, trabalho informal e gênero.

Com base nos conhecimentos teóricos levantados pela pesquisa bibliográfica, foi desenvolvido um estudo exploratório, com abordagem qualitativa. Para a realização deste estudo de campo, foi utilizada a técnica da entrevista semiestruturada, que foi aplicada a nove diaristas que exercem suas atividades laborais em Belo Horizonte, a fim de conhecer como se dão as relações de trabalho nessa conjuntura.

Em síntese, diante do exposto e do conteúdo expresso nas páginas a seguir, esperase que este processo investigativo traga subsídios para o acervo do Serviço Social e demais áreas afins das Ciências Sociais, além de suscitar algumas reflexões sobre o tema em questão.

\section{Informalidade como Condição de Trabalho Precário}

As práticas de organização flexível do trabalho vêm redefinindo os locais de trabalho construídos tanto por trabalhadores qualificados como por trabalhadores sem qualificação. O primeiro grupo é reconhecido por seu saber técnico individual e o segundo, na maioria das vezes, é composto por funcionários subcontratados com rendimentos insuficientes. Esse movimento desencadeou um acelerado processo de terceirização, com base em 
contratos precários de trabalho, o que acabou por fortalecer o mercado informal de trabalho, como consequência das mudanças ocorridas nos padrões de organização do trabalho da década de 1990 (DRUCK, 1999).

Alguns autores apresentam informações relevantes sobre a evolução histórica da informalidade na sociedade brasileira. Inicialmente, Noronha (2003) relata que, no período que compreende as décadas de 1930 e 1940, foram estabelecidas diversas leis para regulamentar o trabalho, no governo corporativista de Getúlio Vargas. A partir de então, foi elaborada a dicotomia entre formal e informal.

De acordo com Neves, Jayme e Zambelli (2006), foi apenas na década de 1970 que, mundialmente, foram elaborados os primeiros questionamentos sobre a configuração do trabalho informal. Com o objetivo de avaliar os efeitos da informalidade sobre o emprego e sobre a distribuição de renda no país e as estratégias de crescimento rápido, surgiu a necessidade de elucidar questões sobre os meios de trabalho não-formais, inclusive, sobre o trabalho autônomo de subsistência e outros de difícil classificação.

No cenário mundial, a década de 1980, conforme Lira (2006), foi decisiva quanto à perda de direitos trabalhistas e sociais, o que afetou, gravemente, a parcela da população que tinha como única alternativa de subsistência o trabalho formal. Com a diminuição dos rendimentos e o aumento do desemprego, tornou-se necessário desenvolver outras formas de inserção laboral, tais como a informalidade. Neves, Jayme e Zambelli (2006) relatam que foi nesse período que ocorreu a ampliação do setor informal em decorrência da crise econômica.

Nesse contexto de crise econômica, conforme Lira (2006, p. 133), nos anos de 1980:

[...] as políticas neoliberais adequam-se ao processo de mudanças no mundo do trabalho. Através delas, promoveu-se uma série de medidas macroeconômicas, visando à adequação das condições econômicas e sociais às leis do mercado, eliminando progressivamente as chamadas regulações governamentais protetoras, acusadas de inviabilizar a expansão, a produtividade e a competitividade do capital.

Ainda sobre esse período, Neri e Fontes (2010) apontam outros fatores, como a reestruturação produtiva e a estagnação da economia, que acirraram o crescimento do setor informal. Para os autores, nesse momento, "a informalidade constituiu o principal 'colchão' que alivia choques trabalhistas adversos naqueles que não podem se dar ao luxo de ficar buscando uma ocupação melhor" (NERI; FONTES, 2010, p. 36). 
No Brasil, esse impacto pode ser percebido, mais claramente, nos anos 1990, quando a reestruturação produtiva, a revolução tecnológica e a abertura da economia ocasionaram aumento do desemprego. Com a contração ${ }^{1}$ da economia, a redução do emprego industrial e a entrada de produtos importados no país, as empresas alteraram o modo de produção e passaram a contratar um número menor de pessoas. Dessa maneira, abriram espaço para a expansão do setor de serviços, do trabalho sem registro em carteira e do número de trabalhadores por conta própria (NEVES; JAYME; ZAMBELLI, 2006). Nesse sentido, segundo, Lira (2006, p.154):

As mutações no mundo do trabalho, acompanhadas das mudanças societárias, mais fortes na década de 1990, promoveram uma rearticulação entre o Estado, o mercado e a sociedade, alterando os padrões de uso e consumo da força de trabalho e da regulação entre capital e trabalho.

Dessa forma, percebe-se que a reestruturação produtiva acarretou transformações no mundo laboral que culminaram no reordenamento das relações e das condições de trabalho. Com a diminuição dos postos de trabalho, o crescimento do desemprego e a dificuldade de inserir novos trabalhadores no processo de produção, a informalidade passou um ocupar espaço significativo no mundo do trabalho (NEVES; JAYME; ZAMBELLI, 2006).

Assim, o trabalho informal tem crescido com o objetivo de atender as necessidades de um grande grupo de trabalhadores excluídos das relações de trabalho formais e das garantias a elas vinculadas (KUYUMIAN; MELLO; SANTOS, 2001).

Soares (2004) classifica algumas formas de trabalho informal como improdutivas, pois estas não objetivam produzir lucro ou mais valia, tais como: os trabalhadores domésticos, os trabalhadores sem vínculo empregatício e os que prestam serviços de limpeza. Contudo, afirma que, mesmo em situações sem relação explícita de assalariamento, existem regras reguladas pelo sistema assalariado, que faz desse tipo de trabalho um instrumento vital para a manutenção do capital.

Lira (2006) compreende a informalidade como uma forma de mascarar o desemprego e de colocar o trabalhador em uma situação de vulnerabilidade social.

\footnotetext{
${ }^{1}$ Conforme o Novíssimo Dicionário de Economia, entende-se por contração a frequente instabilidade das condições econômicas que acarreta períodos de queda da produção e do nível de emprego e declínio dos preços e dos lucros (SANDRONI, 1999).
} 
Entretanto, na conjuntura atual, é entendida como fator vital ao capital e não mais apenas como meio de subsistência do trabalhador.

Tavares (2002, p. 52) concorda com Lira ao afirmar que "o trabalho informal não comporta apenas ocupações excluídas do trabalho coletivo, e menos ainda, que se restringe às atividades de estrita sobrevivência". É necessário, portanto, refutar esse argumento. Para Neves, Jayme e Zambelli (2006, p. 159):

Sob o manto da informalidade coexistem atividades de natureza muito distintas como as microempresas, o trabalhador autônomo, o empregado assalariado sem carteira de trabalho assinada, o pequeno produtor, [...] o empregado doméstico, o trabalhador terceirizado, o trabalho em domicilio, as cooperativas de trabalho.

As autoras reforçam a ideia de que a informalidade está atrelada à não-regulação estatal do trabalho. Dessa forma, ela passa a ser compreendida no escopo de uma economia pouco visível e pouco mensurável, o que dificulta sua análise.

Lira (2006) informa que, nos últimos anos, no contexto brasileiro, as condições precarizadas de trabalho e a redução dos rendimentos têm aumentado, o que acabou por gerar consequências econômicas e sociais para um estrato significativo da população que trabalha. Diante disso, muitos trabalhadores são levados a buscar alternativas na informalidade, inseridos no mercado precário, para que possam suprir suas necessidades básicas. Assim, o trabalho informal tem desempenhado papel expressivo no processo de acumulação do capital, pois, ao reduzir os custos, garante a manutenção e a reprodução de parcela reconhecível do excedente estrutural da força de trabalho.

Destarte, Kuyumjan, Mello e Santos (2001, p. 193) compreendem que:

[...] o informal é uma vertente do mercado que vem aumentando gradativamente para atender a uma leva de trabalhadores excluídos de trabalhos com contratos formais e excluídos da garantia de direitos trabalhistas e, portanto, de formas estáveis de inserção social.

Para as autoras, o trabalho informal é oponente ao formal, em uma mesma dinâmica, porém, não excludente. O conceito de informalidade está vinculado ao de formalidade. Logo, o trabalho formal é definido por meio de critérios estabelecidos no âmbito do mercado e da ordem jurídica, e o trabalho informal, em contrapartida, rompe com o princípio da regulação estatal. Por conseguinte, Kuyumjan, Mello e Santos (2001, p.196) 
asseveram que "o informal deve ser entendido como um campo amplo, difuso e de difícil captura e, portanto, marcado pela heterogeneidade e complexidade".

A divisão entre o trabalho qualificado e não-qualificado amplia-se com o crescimento do desemprego e da informalidade. Para os trabalhadores não-qualificados, a inserção ocupacional ocorre em situações de informalidade, principalmente, para os assalariados sem carteira assinada e para aqueles que trabalham por conta própria (LIRA, 2006). Portanto,

[...] o "estar na informalidade" pode representar um custo social extremamente alto que, nos dias atuais, se agrava à medida que aumenta a parcela da população trabalhadora inserida em ocupações que se caracterizam pela negação de direitos trabalhistas e elevado grau de vulnerabilidade (como enfermidades, acidentes, velhice) (LIRA, 2006, p. 146).

É por isso que Neri e Fontes (2010) apontam que, no contexto brasileiro, ser trabalhador informal representa possuir baixos rendimentos, estar mais exposto à pobreza, não ser incluído no sistema de proteção previdenciária e sentir-se insatisfeito pelo trabalho realizado, devido às condições precarizadas do mesmo.

Assim, pode-se ressaltar que a informalidade é uma categoria de trabalho que possui critérios próprios de organização, cujos princípios são firmados na solidariedade peculiar a esse tipo de trabalho (KUYUMJAN; MELLO; SANTOS, 2001). Logo,

[...] no informal a sobrevivência depende da palavra dada. [...] 0 informal favorece a relação de caráter simples que permite um pacto velado de garantia de clientela. [...] Aceita-se o risco em troca da interação face a face, do preço competitivo e da manutenção dos vínculos sociais (KUYUMJAN; MELLO; SANTOS, 2001, p. 197-198).

Neri e Fontes (2011), tendo como base os dados da PNAD 2008, afirmam que, ao traçar uma caracterização geral da informalidade, é possível inferir que metade da população trabalhadora brasileira encontra-se no setor informal. Os trabalhadores formais auferem maiores rendimentos e os informais carecem de tratamento diferenciado pelas políticas públicas, pois apresentam diversos perfis, além de menor grau de instrução. Muitos desses trabalhadores não estão regulamentados devido à burocracia imposta para a realização do registro formal de trabalho. Os autores expõem, com mais detalhes, esse panorama, ao declarar que: 
[...] a burocracia excessiva e os elevados impostos, inclusive derivados da legislação trabalhista, aliados à incapacidade do setor formal da economia absorver toda mão-de-obra fazem com que grande parte dos trabalhadores brasileiros sobrevivam na informalidade. Houve um expressivo aumento da informalidade nas décadas anteriores, mas uma redução durante a atual onde, entre 2003 e 2009, houve a geração líquida de 9 milhões de empregos formais. Apesar do recente aumento da formalização dos postos de trabalho, a informalidade no Brasil ainda pode ser considerada extremamente alta [...] (2010, p.42).

Ao analisar a informalidade, Noronha (2003) elenca dois tipos de abordagens para estudar esse fenômeno: as econômicas e as sociológicas, que, por conseguinte, são subdivididas. As abordagens econômicas são: (i) velha informalidade: a informalidade é percebida como transitória e típica de sociedades em desenvolvimento; (ii) informalidade neoclássica: a informalidade é entendida como forma de corrigir os efeitos negativos das normas rígidas inerentes ao mercado de trabalho, assim, é positiva; (iii) nova informalidade: a informalidade é tida como uma das causas dos problemas da sociedade, contudo, representa uma mudança de paradigma no mundo do trabalho. É percebida como, relativamente, neutra.

As abordagens sociológicas entendem a informalidade como algo negativo e a subdividem em três: (i) informalidade pobre: a informalidade relacionada a trabalhos precários; (ii) informalidade jurídica: percebida como infração à norma jurídica, pois existe fora do arcabouço legal; (iii) informalidade da globalização: considerada como inalterada, uma vez que sua essência não se alterou, apenas ocorreram mudanças, no mundo do trabalho, que provocaram o aumento do desemprego e dos trabalhos precários e instáveis.

Contudo, não podemos desconsiderar a dificuldade em uniformizar os conceitos sobre o trabalho informal, uma vez que há multiplicidade de opiniões, como já foi exposto anteriormente.

É importante ressaltar que as mudanças que ocorreram no mundo do trabalho se refletiram, de forma multifacetada, na vida do trabalhador, entre estes, das diaristas. Assim, a seguir, serão apresentadas as formas como essas alterações repercutiram na vida dessas trabalhadoras, em especial, das que se encontram na informalidade.

\section{Diaristas e Ausência de Vínculo Empregatício: uma comparação com as empregadas domésticas}


A proposta, neste tópico, é apresentar, a partir da distinção entre o trabalho das empregadas domésticas e das diaristas, a realidade a que estas estão submetidas. Primeiramente, objetiva-se realizar um resgate histórico do trabalho doméstico na realidade brasileira, para, posteriormente, discorrer sobre alguns elementos que descaracterizam o trabalho das diaristas como trabalho doméstico.

Ao analisar a história desse tipo de trabalho, Nascimento $(2009$, p. 22$)$ infere que:

[...] o trabalho doméstico no Brasil, sem dúvida, tem origem no trabalho escravo prestado nas residências dos senhores, com predominância das mulheres, responsáveis por todas as atividades relacionadas com o bem-estar das famílias: cuidados com os recém-nascidos, limpeza e conservação, preparação da alimentação, companhia para os idosos e viúvas etc. Acrescente-se ainda a obrigação de prestação de favores sexuais que originaram várias gerações de "filhos ilegítimos", os quais eram criados como agregados das famílias.

Com base nessa afirmação, Nascimento (2009) argumenta que, ao findar a escravatura, além do preconceito contra o negro, permaneceu o preconceito contra a mulher, que, antes era escrava, e, a partir de então, passa a executar as mesmas tarefas de outrora, mas como empregada doméstica. Algumas residiam com os patrões e outras moravam em suas próprias casas (NASCIMENTO, 2009). Nesse sentido, Priore (2001, p.582) menciona que:

[...] as mulheres negras, por sua vez, após a Abolição dos escravos, continuaram trabalhando nos setores os mais desqualificados recebendo salários baixíssimos e péssimo tratamento. Sabemos que sua condição social quase não se alterou, mesmo depois da Abolição e da formação do mercado de trabalho livre no Brasil. Os documentos oficiais e as estatísticas fornecidas por médicos e autoridades policiais revelam um grande número de negras e mulatas entre as empregadas domésticas, cozinheiras, lavadeiras, doceiras, vendedoras de rua e prostitutas $[\ldots]$.

Antunes e Silva (2004), ao analisar a realidade do trabalho, na sociedade brasileira pós-escravatura, percebem que esta não estava distante da presente na divisão social do trabalho primitivo, uma vez que tanto a mulher livre como as escravas restringiam seu trabalho à esfera doméstica, sendo responsáveis pela subsistência da família e também pela reprodução.

Desse modo, o IPEA (2009) contextualiza o trabalho doméstico, no Brasil, como fruto de um legado histórico patriarcalista e escravocrata, que embute a convergência de desigualdades cumulativas de gênero e raça. Assim, é uma atividade percebida como 
feminina e desempenhada, majoritariamente, por mulheres negras, desvalorizadas econômica e socialmente, marcadas pela precarização, o que subentende tratamento desigual na legislação trabalhista, internamente heterogêneo e imprescindível para a reprodução das famílias.

Moraes (2003) afirma que a divisão familiar que predomina até os dias de hoje insere a mulher no espaço doméstico, para o cuidado da casa e das pessoas. Esse espaço é encarado como privativo do sexo feminino. A partir desse entendimento, supõe-se que:

[...] a corrente de sucessivas desvantagens que a mulher encontrará na vida profissional, quando impedida a apresentar-se no mercado de trabalho, tem relação direta com a questão das atribuições domésticas. As representantes do sexo feminino são iniciadas na vida prática pelo aprendizado das tarefas domésticas, que consumirão parcela de sua vitalidade e de seu talento. Esse aprendizado inclui, por sua vez, habilitação manual e intelectual, e o favorecimento de características psicológicas que as tornem mais aptas para o cumprimento de 'suas tarefas'. A mulher é então educada para 'maternar', cuidar dos outros (MORAES, 2003, 497).

Com base em tais elementos, seja o trabalho doméstico regulamentado ou não, trata-se de uma questão de gênero inscrita nas relações sociais de classe, em uma sociedade em que a mulher é educada para servir o lar e aqueles que nele habitam. Tal construção social segrega a mulher a espaços ocupacionais, na maioria das vezes, relacionados, diretamente, à esfera doméstica ou de práticas de cuidado do outro.

O trabalho das domésticas encontra-se regulamentado pelas seguintes leis: Lei 9.250, de 26 de dezembro de 1995, Lei 8.212, de 24 de julho de 1991, Lei 8.213, de 24 de julho de 1991, Lei 5.859, de 11 de dezembro de 1972; e Lei 11.324, de 19 de julho de 2006, que revoga o dispositivo da Lei $\mathrm{n}$ - 605, de 5 de janeiro de 1949. Além dessas, há a Emenda Constitucional no 72, de 27 de março de 2013, cujo texto "altera a redação do parágrafo único do art. 70 da Constituição Federal para estabelecer a igualdade de direitos trabalhistas entre os trabalhadores domésticos e os demais trabalhadores urbanos e rurais" (BRASIL, 2013), conforme consta no caput da citada emenda.

Em contrapartida, o trabalho das diaristas permanece sem respaldo legal, pois o Art. 10 da Lei 5.859 afirma que apenas "ao empregado doméstico, assim considerado aquele que presta serviços de natureza contínua e de finalidade não lucrativa à pessoa ou à família no âmbito residencial destas, aplica-se o disposto nesta lei" (BRASIL, 1972). A referida Lei, assim como, a Emenda Constitucional não incluem o trabalho da diarista, até então, um 
fenômeno pouco evidente na sociedade brasileira, uma vez que essa modalidade de trabalho cresceu somente nos últimos anos. Como observam alguns estudiosos, grande parte das empregadas domésticas trabalhava e ainda trabalha como mensalista, mesmo que sem carteira de trabalho assinada.

A legislação trabalhista configura a relação de emprego por meio de quatro elementos que devem existir conjuntamente: pessoalidade, subordinação jurídica, onerosidade e não-eventualidade. São esses critérios que determinam se uma profissão será considerada ou não uma relação de emprego, como acontece com as diaristas. Nesse contexto, Vianna (2008, p. 179) afirma que:

[...] considera-se empregado doméstico a pessoa física que mediante remuneração mensal, presta serviços de natureza contínua a pessoa ou a família, no âmbito residencial destas e desde que não possua a atividade desenvolvida qualquer finalidade lucrativa para o empregador.

Nakagawa, Lima e Maruno (2000, p. 13) apresentam definição semelhante ao afirmar que se entende por "doméstico a pessoa física que, com intenção de ganho, trabalha para outras pessoas físicas, no âmbito residencial e de forma não eventual." Dessa forma, as autoras afirmam que o enquadramento das diaristas como domésticas não é aceito, uma vez que quem trabalha como prestador de serviço, por dia, não é assim considerado.

Conforme consulta realizada no Dicionário Jurídico", diarista "é aquele que recebe por dia de trabalho [...]." O Decreto-lei n.o 5.452, de 1을 de maio de 1943, em seu Art. 65, informa que, "no caso do empregado diarista, o salário-hora normal será obtido dividindo-se o salário diário correspondente à duração do trabalho, estabelecido no art. 58, pelo número de horas de efetivo trabalho" (BRASIL, 1943). Desse modo, aquele que trabalha como diarista receberá imediatamente após o trabalho realizado, não sendo obrigado a retornar, caso não esteja interessado.

Nascimento (2009) apresenta algumas características do trabalho das diaristas que são comuns ao trabalho das empregadas domésticas. Segundo ele:

[...] são habituais ou contínuos, como se refere o art. 1으 da Lei 5.859/73, pois são prestados de forma permanente, pouco importando se uma, duas ou três vezes na semana, ao contrário das atividades prestadas de forma eventual, as quais são esporádicas, fortuitas, episódicas e ocasionais; atividades prestadas sob o comando de quem contrata seus serviços, pois nenhuma diarista tem a liberdade

\footnotetext{
${ }^{2}$ Disponível no site http://www.jusbrasil.com.br/
} 
de estabelecer sua rotina e método de trabalho sem a interferência direta e permanente dos donos da residência; na maioria das vezes recebem em contrapartida remuneração diária, o que não descaracteriza o trabalho subordinado; o montante dessa remuneração, se superior ou não àquele recebido pelas empregadas domésticas, também não descaracteriza a relação de emprego doméstico; serviços prestados na residência de quem as contrata sem finalidade lucrativa, caso contrário caracterizaria relação de emprego comum, como já decidiu o TST (NASCIMENTO, 2009, p.36).

De acordo com dados do IPEA (2009, p.14), "entre 1998 e 2008, quase dobrou o número de 'diaristas' (de 856 mil para 1,6 milhão). Passaram de 18,3 \% para 26,5 \% da categoria de trabalhadoras domésticas. Diaristas têm remuneração mais alta (salário direto), mas são menos formalizadas". A jornada de trabalho de uma diarista foi estimada em 33,4 horas semanais. Outro dado observado é que as "diaristas, cujos rendimentos dependem do número de horas trabalhadas, não estariam conseguindo trabalhar tanto quanto gostariam" (IPEA, 2009, p.17).

Portanto, pode-se entender que a ocupação diarista é uma extensão do emprego doméstico, embora apresente algumas especificidades advindas das transformações do mundo do trabalho, fruto de um processo histórico de desregulamentação das profissões. Assim, apresenta características que não são encontradas no trabalho doméstico formal. No entanto, como foi apresentado, existem também diversas características que poderiam proporcionar condições para a formalização do trabalho das diaristas.

A partir dessas informações, será analisado o material coletado em entrevista com nove diaristas, que apresenta, em alguns momentos, opinião favorável ou desfavorável à bibliografia publicada sobre o assunto.

A pesquisa de campo, com abordagem qualitativa, foi desenvolvida por meio de entrevista semiestruturada com nove diaristas do sexo feminino que trabalham no município de Belo Horizonte. Optou-se por realizá-la dessa maneira, uma vez que "seu foco é, principalmente, a exploração do conjunto de opiniões e representações sociais sobre o tema que pretende investigar" (GOMES, 2008, p.79).

A escolha da amostra foi livre, tendo como critérios o sexo das entrevistadas e a condição de informalidade. As entrevistas foram realizadas em momentos distintos, sendo as cinco primeiras em dezembro de 2010 e as outras quatro, em março do ano seguinte. 
Segundo Minayo (2008), a entrevista é a técnica mais utilizada em pesquisas de campo, cujo escopo é levantar informações úteis sobre temas relacionados ao estudo, de modo a contribuir para a consecução do objetivo proposto.

O percurso metodológico ocorreu em seis estágios: (i) formulação de instrumentais; (ii) realização das entrevistas; (iii) transcrição das entrevistas; (iv) revisão do conteúdo junto às entrevistadas; (v) análise de dados, (vi) e produção textual.

Com base em bibliografia sobre a temática, foram formulados os questionamentos que subsidiaram o Roteiro de Entrevista. Também foi redigida a Carta de Apresentação e o Termo de Responsabilidade Ética, que foi entregue a cada diarista, a fim de garantir o sigilo do conteúdo coletado. Optou-se, neste estudo, por não utilizar os nomes das entrevistadas, que são referidas pela letra $D$, seguida de um algarismo de um a nove, grafado em sua forma arábica, respeitando-se a ordem em que ocorreu cada entrevista.

As entrevistas foram gravadas, mediante autorização das diaristas, em local escolhido por elas, sendo a maioria no próprio domicilio. Posteriormente, ocorreu a transcrição literal das gravações, preservando-se a particularidade das falas, sem correção de qualquer natureza.

Após a transcrição, o conteúdo foi apresentado a cada entrevistada, que teve o direito de ratificar, retificar ou explicitar as respostas fornecidas durante as gravações, realizando, assim, as alterações necessárias.

A seguir, serão apresentados os resultados desta pesquisa e as considerações obtidas por meio do conteúdo coletado.

\section{Diaristas e Informalidade: o que pensam elas sobre o assunto?}

A partir da análise dos dados coletados nas entrevistas com as nove diaristas que trabalham no município de Belo Horizonte, foi possível fazer algumas observações.

Das nove mulheres que foram entrevistadas, sete ingressaram no mercado de trabalho informal na função de diarista há mais de três anos. Apenas duas delas desempenham a profissão há um ano. Algumas afirmaram que já trabalharam com registro em Carteira de Trabalho e Previdência Social, o que pode ser observado na fala de D6: 
Porque eu fui trabalhar muitos anos numa casa, e quando fui fazer o acerto, não teve nada. Trabalhei muitos anos numa casa. Treze anos de carteira assinada, e quando eu fui acertar, o acerto que eu tinha era o quê? Férias e aviso, pronto. Então eu achei que não era vantagem pra mim mais. Eu trabalhei (novamente) de empregada doméstica, mas eu não trabalhei de carteira assinada. A mulher nunca assinou a minha carteira, ela só pagava o INSS pra mim, eu nunca (mais) trabalhei de carteira assinada. Não era vantagem pra mim mais. Aí continuei diarista, trabalhando de diarista.

Outra proposta foi perceber a opinião das diaristas em estudo sobre o trabalho informal no âmbito doméstico. O elemento que mais se fez presente foi a inexistência de direitos trabalhistas. Logo, pôde-se perceber que, para o grupo de entrevistadas, trabalhar na informalidade é não possuir direitos trabalhistas, ou seja, não ter os mesmos direitos das demais categorias profissionais, não ter Carteira de Trabalho e Previdência Social assinada, nem segurança no trabalho, entre outros elementos.

Nascimento (2009, p.33), ao discorrer sobre a categoria das diaristas, ratifica essa opinião com a seguinte citação: “Essas diaristas não podem ter acesso aos mesmos direitos trabalhistas e previdenciários das empregadas domésticas, o que caracteriza a precariedade de muitas dessas relações de trabalho."

Em segundo lugar, notou-se, nos relatos das entrevistadas, a relação entre informalidade e ausência de subordinação jurídica: trabalhar por conta própria; independência e flexibilidade para definir a jornada de trabalho; e menor cobrança do contratante do serviço. Com menor menção, destacam-se a eventualidade e o maior rendimento.

D3 explica que, em sua opinião, trabalhar informalmente:

[...] é trabalhar sem carteira assinada e não ter benefício nenhum. Não ter horários para poder trabalhar e você fazer o seu horário e você receber na hora que você trabalha. Pra mim, trabalhar informalmente é não ter carteira assinada. Como eu te disse: é não ter que cumprir horários.

A entrevistada D4 também explica o seu entendimento sobre esse tipo de trabalho:

É um trabalho sem carteira assinada, um trabalho de minha responsabilidade, trabalho por conta própria mesmo. Trabalho informal é um trabalho que você não tem muita segurança, um trabalho que hoje você está trabalhando, amanhã não sabe se vai estar. Mas é um meio de se tirar um salário melhor, de ganhar um pouco mais do que se você estivesse trabalhando de carteira assinada nessa área que eu trabalho, que é diarista. 
Conforme Barreto (2011), nesse tipo de trabalho, não está presente a subordinação jurídica, pois a atividade laboral é dirigida pelo próprio trabalhador. Entretanto, Nascimento (2009, p. 32) discorda tanto das entrevistadas quanto de Barreto, ao afirmar que:

[...] são raros os casos de diaristas que executam tarefas em residências sem a interferência e coordenação direta de seus proprietários, notadamente no que se refere à execução das tarefas domésticas mais corriqueiras como limpar, arrumar, cozinhar etc. Não existe no mundo real do trabalho doméstico a alegada flexibilidade atribuída aos diaristas, de que tratam inúmeras decisões da Justiça do Trabalho. Na verdade, as tarefas são determinadas e devem ser executadas fielmente, ou seja, a maioria dos diaristas presta serviços atendendo as ordens e as necessidades cotidianas de seus contratantes.

O critério de eventualidade não se aplica ao trabalho doméstico, contudo, pode ser observado no trabalho das diaristas, conforme percebido em pesquisa de campo. Dessa forma, o exercício laboral das diaristas é eventual, episódico, desobrigado de continuidade, como observa Vianna (2008).

No entanto, é imprescindível deixar claro que o elemento que torna o trabalho da diarista eventual não é o simples fato de esta trabalhar dois ou três dias na semana, em diferentes residências, mas a desobrigação de continuidade, ou seja, no dia que se encontra na residência de um contratante tem o compromisso de concluir suas atividades. Entretanto, não há nada que fique pendente em relação ao contratante, caso não queira permanecer vendendo sua força de trabalho.

Diante de tais elementos, fez-se necessário compreender o porquê de trabalhar como diarista, uma vez que a maior parte das entrevistadas possui esclarecimento quanto à falta de regulamentação da profissão. Os argumentos mais constantes, nas falas das diaristas, estão relacionados a maiores rendimentos e à menor jornada de trabalho, o que possibilita a conciliação das tarefas domésticas e do cuidado da família. Apenas duas entrevistadas afirmaram optar ou gostar da profissão. Quando questionada, D9 argumenta: "Porque ganha mais. Por causa do horário, você não tem que ficar batendo cartão. Na hora que você termina vai embora, melhor". Acerca da dupla jornada, D8 menciona "eu tenho a minha filha. É mais tranquilo, eu posso trabalhar dois, três dias na semana e não ter compromisso nos outros dias, e ficar por conta dela".

Em relação aos rendimentos, Nascimento (2009, p.32) ressalta que: 
[...] é importante destacar ainda o quantum e a forma como os diaristas são remunerados, devido à alegação de que têm remuneração mais elevada que os domésticos e recebem por dia. A remuneração mais elevada é obtida por duas razões: a primeira, como forma de compensar a falta de reconhecimento do vínculo empregatício, dado que devem arcar por conta própria com sua contribuição previdenciária e de custear o transporte; a segunda, pelo número de contratos que possuem. Na maioria dos casos, recebem valor fixo mensal, independentemente da quantidade de dias trabalhados no decorrer do mês.

Apesar de as diaristas exercerem suas atividades com maior liberdade em relação ao tempo, é notável que assim o fazem para conciliar o trabalho e o cuidado da própria família. Neste contexto, essas mulheres desempenham uma dupla jornada de trabalho, ora na casa do contratante, ora em sua própria residência. Antunes (2009, p.108) analisa esse fenômeno da seguinte forma:

[...] a mulher trabalhadora, em geral, realiza sua atividade de trabalho duplamente, dentro e fora de casa [...].E, ao fazê-lo, além da duplicidade do ato de trabalho, ela é duplamente explorada pelo capital [...] Mas, no universo da vida privada, ela consome horas decisivas no trabalho doméstico, com o que possibilita (ao mesmo capital) a sua reprodução, nessa esfera do trabalho não diretamente mercantil, em que se criam as condições indispensáveis para a reprodução da força de trabalho de seus maridos, filhos/as e de si própria. Sem essa esfera da reprodução não diretamente mercantil, as condições de reprodução de sistema de metabolismo social do capital estariam bastante comprometidas, se não inviabilizada.

As opiniões das mulheres sobre a aspiração de trabalhar formalmente se mostraram divididas entre sim e não. Duas vezes foi mencionado o termo "depende", relacionado ao horário e ao salário. As três entrevistadas que responderam afirmativamente compreendem que, no mundo laboral, só goza de reconhecimento social aquele que trabalha com registro em Carteira de Trabalho e Previdência Social. As mesmas afirmaram também que se submeteriam ao trabalho formal para adquirir a segurança garantida às outras categorias profissionais. Duas das que responderam negativamente demonstraram que podem mudar de opinião, contudo, outras duas disseram que não têm intenção de mudar.

D2, uma das que responderam positivamente, menciona que "trabalharia sem problema nenhum. Porque só dá valor às pessoas que tem carteira assinada, as que não têm, pra eles não é trabalho." Tal afirmativa vem de encontro com análise realizada pelo IPEA (2009), sobre questões relacionadas ao reconhecimento profissional, à 
autovalorização, à autonomia profissional, entre outros, que ocorrem no plano simbólico e têm peso menor para as diaristas em comparação com as domésticas formais.

Já D1 é incisiva em sua opinião, ou seja, não têm intenção de trabalhar formalmente: “Não. Vou trabalhar mais. Vou ganhar menos, entendeu? Jamais. Eu tive oportunidade, fui dois dias e não fui mais".

A partir desses argumentos, fica evidente que, por um lado, deseja-se trabalhar de forma regulamentada para gozar de reconhecimento social, mas, por outro, evita-se a normatização, uma vez que trabalhar formalmente implica em permanecer mais horas no serviço, com constante supervisão dos patrões, além de ter descontos no salário, referentes a tributos sociais, o que acarreta, consequentemente, a redução do mesmo.

Sobre esse assunto, pesquisa realizada pelo IPEA (2009) constatou que "o movimento de formalização do mercado de trabalho nos últimos anos no Brasil não foi sentido na classe das trabalhadoras domésticas," uma vez que, para parte considerável da categoria, trabalhar formalmente representa ônus salarial e também de tempo. Paradoxalmente, essa mesma pesquisa ainda revelou que as diaristas trabalham, em média, 33,4 horas semanais, enquanto as empregadas mensalistas cumprem uma jornada em torno de 37,6 horas. No entanto, a jornada reduzida é atribuída ao fato de as diaristas encontrarem dificuldades para conquistar novos campos de trabalho. Segundo o IPEA (2009, p.17), as diaristas "não estariam conseguindo trabalhar tanto quanto gostariam".

Como vantagens do trabalho informal, as entrevistadas citaram: a jornada de trabalho; a remuneração; a não-subordinação; e, com menor ênfase, a eventualidade. Quanto à jornada de trabalho, as diaristas em estudo utilizaram expressões como: trabalhar pouco; não ter dia certo para trabalhar; fazer o próprio horário; ter tempo para estar com a família; menor carga horária; e não bater cartão. Sobre a remuneração, as principais citações foram: ganhar mais; receber no ato do serviço; fazer o próprio salário; e melhor remuneração. O elemento não-subordinação pode ser percebido quando as entrevistadas dizem: o "patrão não pega no pé"; "não tenho um compromisso"; e “independência". Desse modo, é perceptível a relação que estabelecem com a profissão e o que há de positivo nela.

Muitos desses dados podem ser observados na explanação da entrevistada D9, que indaga: "A vantagem?" e responde logo em seguida: "a vantagem é que você ganha mais e 
não tem que tolerar as patroas todo dia direto; um dia você tá num lugar, outro dia você tá em outro. E não bate cartão". D4 acredita que "a vantagem é que eu faço meu salário e também faço meu horário, eu não tenho um compromisso, [...], não tenho aquela coisa certa que eu preciso chegar tal horário."

Esses argumentos podem ser comparados às conclusões apresentadas por Barreto (2011), quando afirma que as diaristas podem optar de que forma, com quem e onde irão exercer a atividade laboral. Desse modo, elas estão isentas de cumprir horários determinados pelo contratante, gozam de flexibilização em relação aos dias de trabalho e recebem a remuneração imediatamente após realizar o serviço.

Por meio dos elementos expostos nas falas das diaristas pode-se perceber que essas trabalhadoras buscam estratégias para resistir à alienação imposta pelo capital ao trabalhador. Nesse sentido, Aranha e Martins (1993) afirmam que o trabalho tem a capacidade de destruir a liberdade do homem, de aliená-lo e desumanizá-lo, pois submete a massa de trabalhadores de forma impositiva, rotineira e destituída de criatividade.

Desse modo, as diaristas rompem com esse padrão de trabalho, infringindo os aspectos legais, principalmente, os de subordinação jurídica e não-eventualidade. Contudo, são penalizadas ao serem destituídas dos direitos sociais que, por sua vez, assegurariam a proteção social do Estado.

As entrevistadas também apresentaram as desvantagens do trabalho informal. 0 elemento mais citado, quase que por unanimidade, foi a ausência de direitos trabalhistas. D8, ao discorrer sobre o assunto, expõe que "a desvantagem é que se você adoece e não paga INSS, aí é por sua conta. Você vai perder o seu dia tranquilo. Não tem direito a receber nada. E quando você sai também não tem direito nenhum." D9 complementa da seguinte maneira: "você não tem fundo de garantia. Não tem carteira assinada, não tem segurodesemprego. Se você machucar é por conta própria, você vai por conta própria. Se você quiser ter algum futuro você tem que pagar o seu INSS sozinha."

Para Lira (2006), os trabalhadores que se encontram na informalidade vivenciam situações de maior risco e vulnerabilidade no trabalho, o que implica em uma perda acentuada da qualidade de vida e da proteção social. Esse é o grupo mais vulnerável e sem cobertura da previdência social, sem recursos para se preparar para a aposentadoria, que, 
certamente, constituirá o público da assistência social, quando precisar utilizar a proteção social do Estado.

Outra categoria analisada foi a relacionada à condição financeira das diaristas, após ingressarem no mercado de trabalho informal. Do total de entrevistadas, apenas duas apresentaram opinião distinta: uma afirmou que a situação financeira piorou e outra, que se não alterou.

D1 julga que sua condição financeira melhorou, ao afiançar: "Boa, melhor que formal, pelo fato de ganhar mais." D6 informa que "num ponto foi melhor pra mim; num ponto foi, consegui mais coisas trabalhando de diarista de quando eu trabalhei de empregada doméstica." Apesar de acreditar na melhoria das condições de vida, algumas entrevistadas apresentaram mais desvantagens do que vantagens no trabalho informal. Isso pode ser percebido no comentário de D3: "em certos pontos melhorou sim. Porque aquilo que eu faço, eu recebo. Mas, por outro lado, eu não tenho os outros benefícios que eu poderia ter".

Acerca da percepção de como ocorreu o ingresso no trabalho informal como diarista, as entrevistadas responsabilizam: familiares (seja por já trabalharem na área ou por dependerem de cuidados); a si próprias (interesse pelo trabalho); a falta de preparo para atuar em outras áreas (inexperiência formal, baixo grau de escolaridade, ausência de oportunidade em outras áreas); ou não identificam causas.

Quando a entrevistada D1 alega como causa: “Minha mãe, porque já trabalhava. Eu vim da cidade do interior. Não sabia o que fazer. O primeiro que apareceu, eu peguei", responsabiliza a família por seu ingresso na área. Por outro lado, D2 expõe: "ninguém me influenciou a trabalhar desta forma. Foi por minha espontânea vontade mesmo, [...]". Entretanto, completa sua fala dizendo: "por causa da minha família", o que demonstra a causa real. No relato de D4 aparecem elementos semelhantes aos de D1 e D2, como também, a falta de preparo para atuar em outras áreas. Ela diz: "Responsabilidade minha mesmo, eu quis trabalhar informalmente porque eu tive oportunidade. Foi o que apareceu quando estava precisando e pra mim está sendo bom, por enquanto."

Por meio dessas falas, percebe-se a tendência das diaristas de se responsabilizarem pelos efeitos das expressões da questão social em suas vidas. Tal situação repercute na inserção de profissionais em espaços sócio-ocupacionais que exigem maior qualificação 
técnica e elevado grau de escolaridade. Nesse contexto, segundo lamamoto, entende-se por questão social o:

[...] conjunto das expressões das desigualdades sociais engendradas na sociedade capitalista madura, impensáveis sem a intermediação do Estado. Tem sua gênese no caráter coletivo da produção, contraposto à apropriação privada da própria atividade humana - o trabalho -, das condições necessárias à sua realização, assim como de seus frutos. (2000, p.54).

Dessa forma,

A lógica do capital considera as desigualdades sociais como inerentes ao desenvolvimento do capital. A pobreza é encarada como um problema individual e de responsabilidade privada. Ocorre a naturalização da "questão social" e a culpabilização do indivíduo pela sua situação de miséria, o que provoca a perda da dimensão coletiva e desresponsabiliza a sociedade de classes pela produção das desigualdades sociais. (OLIVEIRA, 2006, p. 31-32).

Algumas delas percebem a dificuldade de se inserir em outros campos profissionais, principalmente, em razão do baixo grau de escolaridade e da falta de capacitação técnica. Das nove diaristas entrevistadas, uma é analfabeta, outra possui quatro anos de escolaridade, seis frequentaram a escola durante oito anos (pelo menos) e somente uma completou o ensino médio.

Quanto ao quesito ter frequentado um curso técnico, cinco diaristas informaram que não tiveram oportunidade e quatro realizaram curso na área de estética (manicure, cabeleireira) ou administrativa (secretariado, informática, departamento pessoal). Contudo, não desempenharam a função.

Destarte, pode-se inferir que o binômio baixo grau de escolaridade/ausência de capacitação profissional é fator condicionante para a exclusão das diaristas de outros campos profissionais, uma vez que estas vivem em uma época de crescente especialização das profissões e de maior exigência quanto à formação escolar. De modo geral, para a inserção em grande parte dos espaços sócio-ocupacionais, exige-se, no mínimo, a conclusão do ensino médio. 


\section{Considerações Finais}

A partir do conteúdo apresentado neste artigo, pretende-se desenvolver algumas inferências e considerações sobre o tema abordado. Neste estudo, o trabalho é entendido como esforço de sobrevivência, que, na configuração atual, limita a liberdade humana, uma vez que é mercadoria em processo contínuo de desvalorização, seja em termos de reconhecimento do trabalhador, seja pelo baixo valor pago pelo trabalho.

Com o processo de reestruturação produtiva e acumulação flexível, ocorreu o aumento do desemprego estrutural e, consequentemente, o crescimento do setor de serviços, que acabou por fortalecer o mercado informal de trabalho. A informalidade mostra-se como única possibilidade para aqueles que não são absorvidos pelo mercado formal, que, por sua vez, exige um elevado grau de qualificação técnica.

O trabalho das diaristas é entendido como improdutivo, sem desconsiderar que, ao mesmo tempo, este proporciona as condições para que o trabalho produtivo continue a acontecer na sociedade capitalista. Em seu trabalho, não visam, diretamente, à produção de lucro ou mais valia, mas atendem as necessidades dos que se ocupam dessas atividades, e nisso encontram o reconhecimento social da ocupação.

Tais trabalhadoras desempenham, em seu processo de trabalho, funções idênticas às das empregadas domésticas, sem cumprir, cabalmente, os quatro elementos que configuram as relações de emprego (pessoalidade, subordinação jurídica, onerosidade e não-eventualidade), apesar de, algumas vezes, se enquadrarem em um ou mais deles. Ainda, tal condição não lhes possibilita gozar dos mesmos direitos usufruídos pelas empregadas domésticas.

O trabalho exercido pelas diaristas tem a sua inscrição na divisão social do trabalho, que reserva às mulheres as funções pertinentes à esfera doméstica. No entanto, o trabalho dessas mulheres ocorre de modo ainda mais precário, já que acontece na informalidade, isento das conquistas já obtidas pela categoria das empregadas domésticas. É importante salientar que, graças à semelhança com o trabalho da dona de casa, as atividades que as diaristas realizam são ainda mais desvalorizadas, devido à construção social do trabalho doméstico não se constituir como trabalho propriamente dito. Essa concepção se torna ainda mais complexa quando se considera que a categoria das diaristas, a partir de uma 
perspectiva jurídica, não preenche os critérios que caracterizam as relações de trabalho formal.

Contudo, entende-se que a ocupação diarista é uma mutação do emprego doméstico, com alterações advindas das transformações ocorridas no mundo do trabalho, que vem buscando legitimação social a apresenta uma tendência de aumento expressivo em relação ao número de trabalhadoras.

Com base nas entrevistas realizadas, foi possível perceber que as diaristas compreendem a vulnerabilidade e os riscos a que estão expostas como profissionais, uma vez que se encontram, totalmente, desprotegidas do arcabouço legal (trabalhista e previdenciário), instrumentos estes de proteção social da sociedade capitalista.

Apesar de encontrarem vantagens no trabalho que executam, as entrevistadas não refletem sobre a situação precária a que estão submetidas, justificando tais condições, principalmente, pelos maiores rendimentos obtidos após o trabalho realizado, pela menor carga horária de trabalho e pela ausência de supervisão direta por parte dos patrões. Assim, não levam em consideração os prejuízos que podem ter, em longo prazo, caso se mantenham, por muitos anos, nessas mesmas relações de emprego.

As entrevistadas parecem também não perceber as condições históricas e materiais que as levaram a trabalhar como diaristas. Muitas vezes, em suas falas, culparam-se por trabalhar na informalidade e mostraram entender apenas que não tiveram capacitação adequada ou oportunidade em outros espaços sócio-ocupacionais. Nesse sentido, desconsideram a estrutura classista da sociedade capitalista, que segrega determinadas classes sociais para profissões de baixo status social, com baixa remuneração e pouca ou nenhuma chance de crescimento profissional e ascensão social.

Desse modo, entende-se que a ocupação diarista surgiu da necessidade do capitalismo, que tem sucateado o trabalho dessas profissionais, impossibilitando-lhes o acesso a direitos já conquistados por outras categorias profissionais.

\section{Referências}

ARANHA, Maria Lucia de Arruda; MARTINS, Maria Helena Pires. Filosofando: introdução à filosofia. 2.ed. São Paulo: Editora Moderna, 1993. 
ANTUNES, Ricardo; SILVA, Maria Aparecida Moraes (orgs.). O Avesso do Trabalho. 1. ed. São Paulo: Expressão popular, 2004.

ANTUNES, Ricardo. Os Sentidos do Trabalho: ensaio sobre a afirmação e a negação do trabalho. 2. ed. São Paulo: Boitempo, 2009.

BARRETO, Márcia Ferreira. Diaristas: Ausência de Liame Empregatício. Disponível em: <http://www.jurisway.org.br/v2/dhall.asp?id dh=4558>. Acesso em: 20 maio 2011.

BRASIL. Constituição da República Federativa do Brasil de 1988.

BRASIL. Emenda Constitucional № 72, de 02 de abril de 2013.

BRASIL. Lei no 5.452, de 01 de maio de 1943.

BRASIL. Lei no 5.859, de 11 de dezembro de 1972.

Dicionário Jurídico on line. Diarista. Disponível em: <http://www.jusbrasil.com.br/> Acesso em: 27 jun. 2011.

DRUCK, Maria da Graça. Globalização e Reestruturação Produtiva: o fordismo e/ou japonismo. São Paulo: Revista de Economia Política, v. 19, n. 2, abr.-jun. p. 31-48, 1999.

GOMES, Romeu. Análise e Interpretação de Dados de Pesquisa Qualitativa. In: MINAYO, Maria Cecília de Souza (Org.). Pesquisa Social: teoria, método e criatividade. 27. ed. Petrópolis, RJ: Vozes, 2008.

IAMAMOTO, Marilda Villela. Transformações societárias, alterações no mundo do trabalho e Serviço Social. Questão Social e Serviço Social, Brasília, no 6, jan/jun 2000.

IPEA. Trabalho Doméstico Remunerado: desigualdades de gênero e raça. Brasília, 2009. Disponível em: < http://www.ipea.gov.br/sites/000/2/comunicado presidencia/09 10 07 ComunicaPresi 32 Apresentacao PNAD2008 Trabalho.pdf>. Acesso em: 12 fev. 2011.

KUYUMJAN, Márcia de M. M.; MELLO, Maria T. F. Negrão de; SANTOS, Carolina Cássia Batista. Vivências Cotidianas do Trabalho Informal em Brasília. Ser Social: revista do Programa de pós-graduação em Política Social. Brasília: SER Social UnB. v. 1, n. 9, jul.dez. 2001.

LIRA, Izabel Cristina Dias. Trabalho Informal como Alternativa ao Desemprego: desmistificando a informalidade. In: SILVA, Maria Ozanira da; YAZBEK, Maria Carmelita. Políticas Públicas de Trabalho e Renda no Brasil Contemporâneo. São Paulo: Cortez; São Luiz, MA: FAPEMA, 2006.

NAKAGAWA, Lídia Matico; LIMA, Neusa Maria Corona; MARUNO, Neusa. Conheça Tudo Sobre Empregada Doméstica. 5.ed. São Paulo: LTr, 2000. 
MINAYO, Maria Cecília de Souza (Org.). Pesquisa Social: teoria, método e criatividade. 27. ed. Petrópolis, RJ: Vozes, 2008.

MORAES, Maria Lygia Quartim de. Cidadania no Feminino. In: PINSKY, Carla Bassanezy; PINSKY, Jaime et al. (org). História da Cidadania. São Paulo: Editora Contexto, 2003, p. 495- 515.

NASCIMENTO, Manoel Veras. Diarista: empregado, eventual ou autônomo?: o dilema permanente da Justiça do Trabalho. Revista de direito UPIS, Brasília-DF: v.7 2009.

NERI, Marcelo; FONTES, Adriana. Informalidade e Trabalho no Brasil: causas, conseqüências e caminhos de Políticas Públicas. In: BOUR, Juan Luis et al. Informalidade Laboral na América Latina. Rio de Janeiro: Konrad-Adenauer-Stiftung, 2010.

NEVES, Magda de Almeida; JAYME, Juliana Gonzaga; ZAMBELLI, Paulina. A Nova Informalidade: o trabalho dos camelôs no cenário urbano de Belo Horizonte. Ser Social: revista do Programa de pós-graduação em Política Social. Brasília: SER Social UnB. v. 1, n. 19, jul.- dez. 2006.

NORONHA, Eduardo. G. "Informal", ilegal e injusto: percepções de mercado de trabalho no Brasil.Revista Brasileira de Ciências Sociais, São Paulo: vol.18, no 53, Out. 2003.

OLIVEIRA, Mariana Camargo Tumonis. Benefício de Prestação Continuada e Serviço Social: direito social ou assistencialização do direito? 2006. $111 \mathrm{f}$. Trabalho de Conclusão de Curso (Graduação em Serviço Social) - Universidade Federal do Rio de Janeiro.

PRIORE, Mary Del (org.). História das Mulheres no Brasil. 4. ed. São Paulo: Contexto, 2001. SANDRONI, Paulo (org.) Novíssimo Dicionário de Economia. São Paulo: Editora Best Seller, 1999.

SOARES, Marcos Antonio Tavares. Trabalho informal: da funcionalidade à subsunção formal ao capital. In: IX Encontro da Sociedade Brasileira de Economia Política. Uberlândia, jun. 2004. Disponível em. Acesso em: 17 fev. 2011.

TAVARES, Maria Augusta. Trabalho informal: os fios (in)visíveis da produção capitalista. Revista Outubro, São Paulo, n. 7, p. 2002. Disponível em: <www2.fae.edu/galeria/getlmage/1/361633460249798.pdf > . Acesso em: 18 mar. 2011. VIANNA, Claudia Salles Vilela. Manual Prático das Relações Trabalhistas. 9. Ed. São Paulo: LTr, 2008. 